\title{
Ultrasound Evaluation of Lower Uterine Segment in Pregnant Patient with History of Hysterotomy
}

\author{
Emad Abd El Rahman El-Tamamy, Khaled Gaber Sabaa, Ahmed Khaled Wally Momen* \\ Department of Obstetrics \& Gynecology, Faculty of Medicine, Al-Azhar University \\ *Corresponding author: Ahmed Khaled Wally Momen, Mobile: (+20)01223456741, E-Mail: wallypopo90@gmail.com
}

\begin{abstract}
Background: ultrasonography has been widely used in the field of obstetrics \& gynecology. Development of more sophisticated technology in ultrasonography \& the huge amount of studies \& education by physicians makes ultrasonographic examination one of the most useful diagnostic techniques in obstetrics \& gynecology.

Objective: In this study we aimed to evaluate the gravid uterus in women with a history of previous, 1 or more hysterotomy, in all 3 trimesters by Trans-vaginal ultrasound (TVUS).

Patients and Methods: This is a prospective, case-control, observational study. The study was carried out in a private Obstetrics \& Gynaecology center Wally center in Fayoum city. The study was carried out in the period from December 2017 to December 2018. Initially, 100 patients were enrolled, but at the end of the study only 67 patients were involved in the study.

Results: The distance between the leading edge of the placenta to the internal OS is the diagnostic accretion. This difference between the 5 groups regarding this distance was found to be highly significant $(\mathrm{p}$-value $=0.001)$ across all 3 trimesters, which proves that repeated CS deliveries is a major risk factor for placenta praevia. There were 1 case, 3 cases \& 2 cases of low-lying placenta found in groups $3,4 \& 5$, respectively.

Conclusion: Cesarean section scar pregnancy and rupture uterus are both rare events and were not found in the sample of this prospective study. However, they are both very important to diagnose as early as possible to prevent serious morbidity and even mortality.
\end{abstract}

Keywords: TVUS, Lower uterine segment, CS, Hysterotomy

\section{INTRODUCTION}

Gynecologic ultrasonography refers to the application of medical ultrasonography to the female pelvic organs (specifically the uterus, the ovaries, and the Fallopian tubes) as well as the bladder, the adnexa, and the Pouch of Douglas. The procedure may identify other medically relevant findings in the pelvis $^{(1)}$.

The examination can be performed by transabdominal ultrasound, generally with a full bladder which acts as an acoustic window to achieve better visualization of pelvis organs, or by transvaginal ultrasound with a specifically designed vaginal probe or transducer. Transvaginal imaging utilizes a higher frequency imaging, which gives better resolution of the ovaries, uterus and endometrium (the fallopian tubes are generally not seen unless distended), but is limited to depth of image penetration, whereas larger lesions reaching into the abdomen are better seen by transabdominal ultrasound ${ }^{(2)}$. Having a full bladder for the transabdominal exam is helpful because sound travels through fluid with less attenuation to better visualize the uterus and ovaries which lies posterior to the bladder. The procedure is by definition invasive when performed transvaginally ${ }^{(3)}$.

Gynecologic sonography ${ }^{(2)}$ :

1. Assess pelvic organs.

2. Diagnose acute appendicitis.

3. Diagnose and manage gynecologic problems including endometriosis, leiomyoma, adenomyosis.
4. Diagnose \& management of ovarian cysts and lesions

5. Identify adnexal masses.

6. Diagnosis of ectopic pregnancy.

7. Diagnose gynecologic cancer.

8. Infertility treatments \& follow up.

Obstetric ultrasonography is the use of medical ultrasonography in pregnancy, in which ultrasound waves are used to create real-time visual images of the developing embryo or fetus in its mother's uterus ${ }^{(4)}$. The procedure is a standard part of antenatal care, as it can provide a variety of information about the health of the mother, the timing and progress of the pregnancy, and the health and development of the embryo or fetus ${ }^{(2)}$.

Hysterotomy is a surgical procedure that involves making an incision in the uterus to remove uterine contents in the endometrium. It can be performed for various reasons including caesarian section, intra uterine fetal surgery, delayed surgical miscarriage (>14 weeks). Hysterotomy is the widely preferred technique for open fetal surgery. Hysterotomy procedure is done the same way as caesarian section $^{(5,6)}$. Pfannensteil incision is done, dissection of abdominal wall layers, mobilization of the Urinary bladder \& Transverse incision of the LUS of the uterus in smiley shape.

Hysterotomy is a major surgical operation that is associated with a number of serious risks and complications including $^{(6)}$ :

- Infection (e.g. Peritonitis, surgical site infection). 
- Thromboembolism.

- Pulmonary complications (e.g. ARDS)

- Complication of anesthesia

- Rupture of the operation scar in a future pregnancy

- Hemorrhage (Antepartum \& postpartum) in future pregnancy

- DIC

- Injury to nearby organs (GIT, Urinary bladder, ureters)

- Complications of Laparotomy (e.g. Adhesions, IO, Paralytic ileus)

\section{Aim of the work:}

The study aims to evaluate the gravid uterus in women with a history of previous, 1 or more hysterotomy, in all 3 trimesters by Trans-vaginal ultrasound (TVUS).

\section{PATIENTS AND METHODS}

Study design \& participants:

This is a prospective, case-control, observational study. The study was carried out in a private obstetrics \& gynaecology center (Wally center) in Fayoum city. The study was carried out in the period from December 2017 to December 2018.

The study protocol was initially approved by the obstetrics \& gynecology department of Al-Azhar University, and then the protocol was approved by the Ethics Committee of the Faculty of Medicine. Informed consent was taken orally $\&$ in writing from every patient $\&$ their spouse to use their case findings \& medical records in this study after ensuring complete anonymity.

Initially, 100 patients were enrolled, but at the end of the study only 67 patients were involved in the study. The patients were enrolled initially at the first antenatal visit between 5- 10 weeks of gestation (WOG), this is when their pregnancy was confirmed by laboratory BHCG measurement \& by TV US confirmation. The cases were enrolled into one of five groups according to the number of previous CS deliveries they had:

- Group 1: Primi-gravidas.

- Group 2: Previous 1 Cesarean section delivery (CSD).

- Group 3: Previous 2 CSD

- Group 4: previous 3 CSD

- Group 5: previous 4 CSD

The patients' notes were reviewed from the center's archive to elucidate their past medical, surgical \& obstetric history including any information that meets the exclusion criteria during their previous ANC visits, intra-operative or postpartum period. The indications of the previous CSDs were also reviewed.

No subjects with previous ANC or intraoperative complications were included in the study. All patients were subjected to the following:
1. History taking (focusing on: past history surgically \& medically \& Obstetric History).

2. Clinical assessment of the patient (full general assessment including chest, cardiac, abdominal, limb \& spine examination)

3. Routine Antenatal care including measuring SFH, immunization, supplements.

4. Obstetric Ultrasound using both Transvaginal \& Transabdominal ultrasound by the same observer to:

- Evaluate fetal biometric parameters (CRL, BPD, HC, OFD, AC, FL).

- Measurement LUS myometrial thickness in different trimester.

- Measurement of the retroplacental myometrial thickness.

- Measurement of the distance from the leading placental edge to the internal cervical os.

- Doppler imaging :- placental bed in the $1^{\text {st }}$ trimester, Umbilical artery \& Uterine artery at 24-28 WOG \& again in 32 WOG plus MCA

- Placental site throughout the pregnancy, grade, adhesions \& other pathological features. If low-lying placenta was found or PAS was suspected the patient was referred to a specialist radiological center for confirmation by US or MRI (if deemed necessary by the consultant diagnostic radiologist)

- Evaluation of UB wall for abnormal contour or blood flow between low lying placentas.

5. Laboratory :

- Complete blood count \& Blood typing including Rh status.

- Complete urine analysis (Proteinuria, RBCs or pus cells)

- GDM screening by 75 gm OGTT during $2^{\text {nd }}$ Trimester visit.

6. Preoperative investigations (coagulation profile KFT, LFT, ECG)

\section{Inclusion criteria:}

- Singleton pregnancy.

- If there is history of CS delivery, it was low- transverse incision.

- Medically free.

- Surgically free. (other than previous CSD)

- Able to give informed consent.

- Detailed history of previous CSD.

- Planned elective LSCS at 37-40 WOG.

\section{Exclusion criteria:}

- Patients with any medical disease (DM, Hypertension)

- History of surgery involving abdominopelvic cavity. 
- Oligo- or polyhydramnios

- Fetus without normal development throughout the ANC (e.g. SGA, IUGR, PTD).

- Women with obstetric complications requiring intervention (e.g. Miscarrige, PPROM)

- Age: < 18 years old or > 35 years old.

- BMI :- $<25$ or > 35

- Any congenital or structural anomalies.

- Missed ANC appointments.

\section{Ultrasound examination:}

A 2D greyscale, Mindray DC-70 machine with Trans-vaginal (5-9 MHz) \& Trans-abdominal (2-7 MHz) curved array probes was used. The recorded measurements, including those related to the study \& those of routine ANC were saved in the machine's Hard-drive with each patient having a specific Code number.

Measurement of the myometrial thickness was done using the TV US probe. 4 measurements were taken at each scan $\&$ the thinnest measurement was recorded, this was done to minimize intraobserver variability \& measurement bias. This was done once in each trimester of the pregnancy, in the $1^{\text {st }}$ trimester, between $12-14 \mathrm{WOG}$, in the $2^{\text {nd }}$ trimester between $20-22$ WOG $\&$ in the $3^{\text {rd }}$ trimester between 34- 36 WOG. The myometrial thickness was measured as shown in (figure 1) \& not the whole LUS thickness. Special care was taken to dislodge the fetal head if it was pressing on the LUS especially in the $3^{\text {rd }}$ trimester when the fetal weight is increased \& can cause thinning of the myometrial thickness. Additionally, the bladder was empty during the measurement to avoid the same effect on the LUS thickness. The estimated fetal weight was calculated using preset equation in the US machine by measuring BPD, HC, AC \& FL. Measurement of the myometrial thickness was done when the EFW was within a certain range, which was; $80-110 \mathrm{gm}$ in $1^{\text {st }}$ trimester, 400-500 gm in $2^{\text {nd }}$ trimester \& 2500-2900 gm in $3^{\text {rd }}$ trimester (Table 1$) \&$ any case were the fetal shows growth restriction or large for GA was excluded from the study.

Table (1): The mean \& range of the estimated fetal weight during each $\operatorname{scan}^{(7)}$.

\begin{tabular}{|c|c|}
\hline $\begin{array}{c}\text { Gestational age } \\
\text { (weeks of gestation } \\
\text { WOG) }\end{array}$ & $\begin{array}{c}\text { Estimated fetal weight } \\
(\mathrm{gm})\end{array}$ \\
\hline $12-14$ & $95(80-110)$ \\
\hline $20-22$ & $465(400-500)$ \\
\hline $34-36$ & $2690(2500-2900)$ \\
\hline
\end{tabular}

Measurement of the retro-placental myometrial thickness was done using both TV \& TA US probes, 4 measurements were taken by each \& only the thinnest reading was recorded. Care was taken to walk through the whole placenta \& sample measurement of every part in order to avoid missing of the thinnest Retro-placental RMT. Measurement of the leading edge to internal os was taken. First, sliding of the probe across the lower most edge of the placenta in order to detect if there is lateral extension or marginal placenta praevia. The internal os was identified by the upper end of the endo-cervical canal $\&$ if not clear, a point opposite the roof of a semiempty urinary bladder was used. If low-lying placenta was detected, the placenta praevia algorithm of GTG was carried out (figure 2) ${ }^{(\mathbf{8})}$.

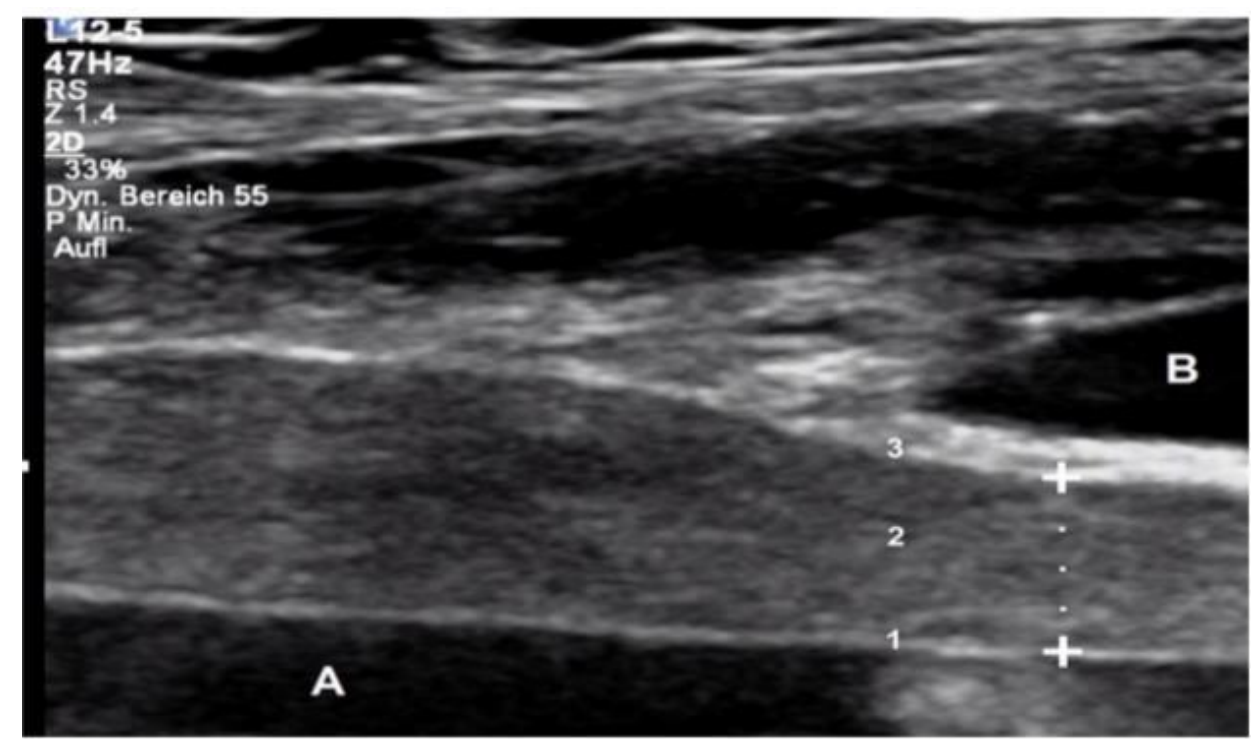

Figure (1): Illustration of Measurement of LUS myometrial thickness. A: Amniotic fluid, B: Urinary Bladder, 1: position of inner caliper placement, 2: myometrial layer of LUS, 3: Position of outer caliper placement $^{(7)}$. 


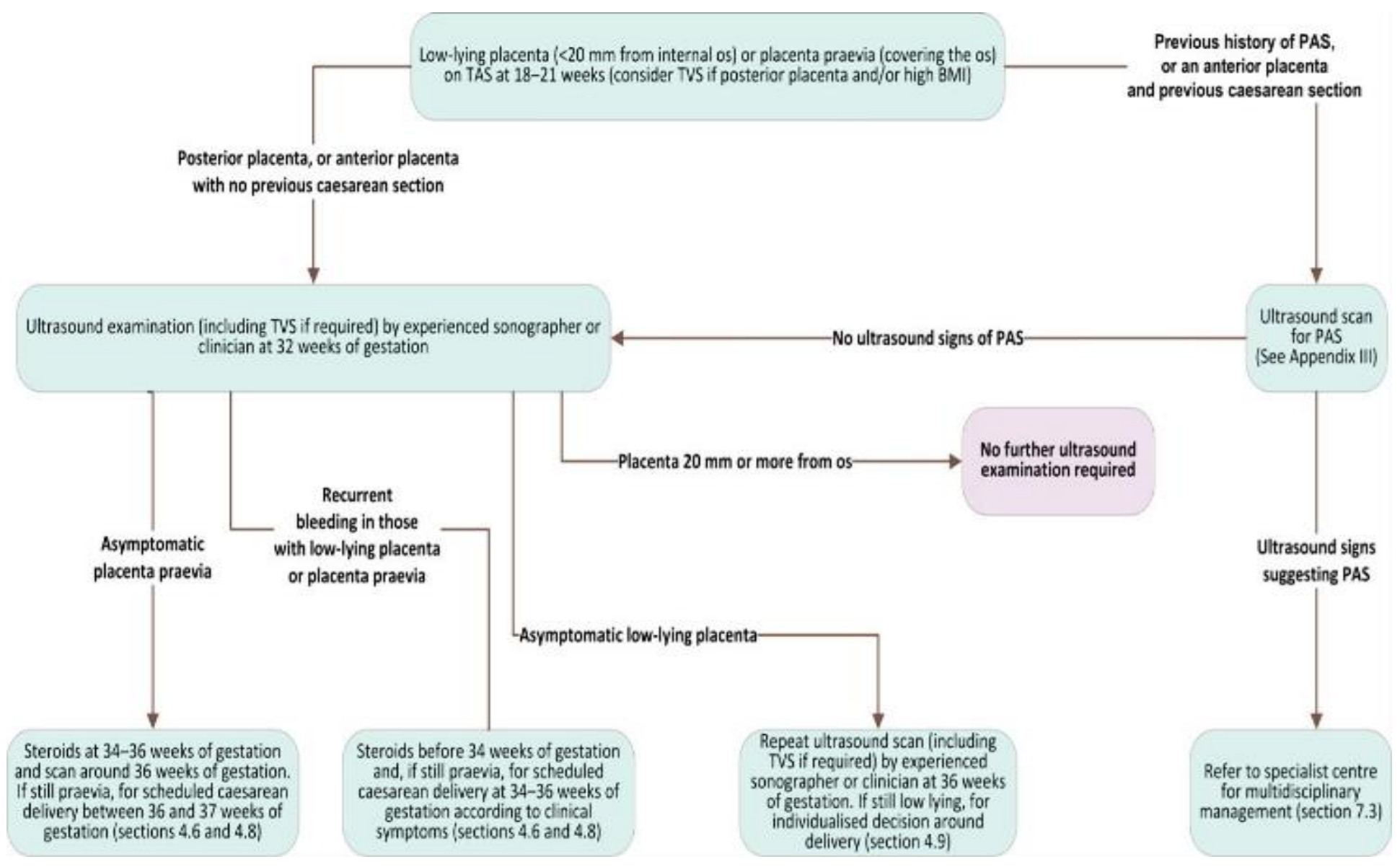

Figure (2). Algorithm of management of low-lying placentae or placenta praevia ${ }^{(8)}$.

Intra-operative adhesions were assessed before \& after the hysterotomy incision was done. Naturally, the result was subjective \& operator dependent, so the same operator surgeon assessed the degree of adhesions. If adhesions were present, they were categorized into 3 degrees:

\section{$1^{\text {st Degree: }}$}

1) No or minimal, thin filmy adhesions not affecting the structures surrounding the LUS.

2) Simple dissection of the utero-vesical fold of peritoneum

$2^{\text {nd }}$ degree (moderate):

1) Urinary bladder pulled up, but mobile after dissection of the UV fold of peritoneum

2) Band of adhesion with the omentum $>1 \mathrm{~cm}$ thick at site of adhesion on the uterine wall, and require only monopolar diathermy to be divided.

$3^{\text {rd }}$ degree (marked):

1) Band of adhesion $<1 \mathrm{~cm}$ thick at site of adhesion on the uterine wall involving the peritoneum, omentum or loop of intestine.

2) Uterus could not be exteriorized \& extraperitoneal CSD was done.
3) Anterior uterine wall adherent to the overlying anterior abdominal wall.

\section{Statistical Analysis}

- Data were collected and coded and double entered into Microsoft Access and data analysis was performed using Statistical Package of Social Science (SPSS) software version 18 in windows 7.

- Simple descriptive analysis in the form of numbers and percentages for qualitative data, and arithmetic means as central tendency measurement, standard deviations as measure of dispersion for quantitative parametric data.

- Quantitative data included in the study was first tested for normality by One-Sample Kolmogorov-Smirnov test in each study group then inferential statistic tests were selected.

- For quantitative parametric data :

- In-depended student t-Test used to compare measures of two independent groups of quantitative data

- One way ANOVA test in comparing more than two independent groups of quantitative data 


\section{- For qualitative data:}

- Chi square test to compare two of more than two qualitative groups.

- General linear model to compare repeated measures

The $\mathbf{P}$-value $\leq \mathbf{0 . 0 5}$ was considered the cutoff value for significance.

\section{RESULTS}

In the period between December 2017 to December 2018, 100 patients were selected to this study, after they met the required criteria. However, at the end only 67 patients finished the study, the cause of elimination of those 33 patients is reported in table (2). The numbers of TV US measurements were 12 per patient, 4 in each trimester, in addition to the imaging done for normal ANC. The results of these measurements are reported in tables (10-14).As expected the mean LUS myometrial thickness is decreased as the gestation proceeded \& decrease as the number of previous CSDs increase.

One case out of 11 patients with previous 2 CS had placenta praevia, 1 in 11 patients with previous $3 \mathrm{CS}$, in addition to 2 others with low-lying placentae but not praevia. Finally 2 patients with previous 4 CS (group 5) had placenta praevia \& lowlying placentae, respectively the RR of low-lying placentae \& placenta praevia was found to be 9 in group 3, 27 in group $4 \& 22.2$ in group 5 .

Placenta accrete spectrum (PAS) was found intra-operatively in 2 cases of previous $3 \mathrm{CS}$ deliveries (group 4) \& 2 cases of previous 4 CS (group 5). The retro-placental thickness was affected in 1 case of the group $4 \&$ the 2 cases of group 5 patients. Another patient in group 5 had loss of retroplacental RMT in the $3^{\text {rd }}$ trimester \& placenta praevia but placenta accrete was excluded after placenta separation \& inspection. Therefore, 4 out of 44 patients with history of CS had PAS with an overall incidence of $9 \%$, while $18 \%$ of previous 3 CS \& $22.2 \%$ of previous $4 \mathrm{CS}$ had PAS. The sensitivity was $75 \%$. No placenta percreta was found in this study.

Step-wise devascularization of the uterus was done in all 5 cases of low-lying anterior placentae, B- Lynch compression suture was done in 2 cases out of which 1 case preceded to supra-cervical cesarean hysterectomy. This represents $1.49 \%$ of the cases in my study \& $20 \%$ of cases with PAS cases, study 1 out of $9(11 \%)$ patients with previous 4 CS deliveries had done hysterectomy.

\section{Table (2). Showing the cause $\&$ number of} excluded cases

\begin{tabular}{|l|c|}
\hline \multicolumn{1}{|c|}{ Cause of exclusion } & $\begin{array}{c}\text { Number of } \\
\text { cases }\end{array}$ \\
\hline First trimester miscarriage & 4 \\
\hline Preterm birth $(<36$ WOG $)$ & 3 \\
\hline Congenital abnormality & 1 \\
\hline PROM & 5 \\
\hline Small for gestational age & 2 \\
\hline Gestational diabetes & 2 \\
\hline $\begin{array}{l}\text { Pregnancy induced } \\
\text { hypertension }\end{array}$ & 4 \\
\hline Drop outs & 11 \\
\hline Ante-partum hemorrhage & 2 \\
\hline
\end{tabular}

Table 3 illustrates that there is statistically significant difference with $\mathrm{p}$-value $<0.05$ between different study groups as regards lower uterine segment thickness in all three trimesters with higher mean thickness was noted among group 1 in three trimesters, but the lowest mean thickness was noted among group 4 in $1^{\text {st }}$ trimester, among group 5 in $2^{\text {nd }}$ and $3^{\text {rd }}$ trimesters.

Table (3): Comparisons of lower uterine segment thickness in different study groups.

\begin{tabular}{|l|c|c|c|}
\hline \multirow{2}{*}{ Groups } & \multicolumn{3}{|c|}{ Lower uterine segment thickness } \\
\cline { 2 - 4 } & $\mathbf{1}^{\text {st }}$ trimester & $\mathbf{2}^{\text {nd }}$ trimester & $\mathbf{3}^{\text {rd }}$ trimester \\
\cline { 2 - 4 } & Mean \pm SD & Mean \pm SD & Mean \pm SD \\
\hline Group 1 $(\mathrm{n}=16)$ & $\mathbf{1 4 . 8 3} \pm \mathbf{2 . 4} *$ & $\mathbf{1 0 . 2 5} \pm \mathbf{0 . 9 8}$ & $\mathbf{3 . 7 8} \pm \mathbf{0 . 7}$ \\
\hline Group 2 $(\mathrm{n}=13)$ & $12.22 \pm 2.2$ & $8.28 \pm 1.5$ & $3.41 \pm 0.62$ \\
\hline Group 3 $(\mathrm{n}=11)$ & $13.84 \pm 1.5$ & $8.62 \pm 1.02$ & $3.21 \pm 0.47$ \\
\hline Group 4 $(\mathrm{n}=11)$ & $\mathbf{1 1 . 5 9} \pm \mathbf{1 . 8}$ & $8.13 \pm 1.4$ & $2.96 \pm 0.61$ \\
\hline Group 5 $(\mathrm{n}=9)$ & $12.19 \pm 1.5$ & $\mathbf{5 . 8 3} \pm \mathbf{1 . 2} *$ & $\mathbf{2 . 6 8} \pm \mathbf{0 . 3 5}$ \\
\hline p-value & $<\mathbf{0 . 0 0 1}$ & $<\mathbf{0 . 0 0 1}$ & $<\mathbf{0 . 0 0 1}$ \\
\hline Sig. & $\mathbf{H S}$ & $\mathbf{H S}$ & $\mathbf{H S}$ \\
\hline
\end{tabular}

Table 4 illustrates that there is statistically significant difference with p-value $<0.05$ between different study groups as regards length between placenta and uterine OS in all three trimesters with taller length was noted among group 1 in three trimesters, but the shortest length was noted among group 4 in $1^{\text {st }}$ and $3^{\text {rd }}$ trimester, and among group 5 in $2^{\text {nd }}$ trimesters. 
Table (4): Comparisons of Placenta to Os length in different study groups

\begin{tabular}{|l|c|c|c|}
\hline \multirow{2}{*}{ Groups } & \multicolumn{3}{|c|}{ Placenta to Os length } \\
\cline { 2 - 4 } & $\mathbf{1}^{\text {st }}$ trimester & $\mathbf{2}^{\text {nd }}$ trimester & $\mathbf{3}^{\text {rd }}$ trimester \\
\cline { 2 - 4 } & Mean \pm SD & Mean \pm SD & Mean \pm SD \\
\hline Group 1 $(\mathrm{n}=16)$ & $\mathbf{3 4 . 2 5} \pm \mathbf{1 1 . 6} *$ & $\mathbf{6 1 . 1 3} \pm \mathbf{7 . 2}$ & $\mathbf{9 9 . 7 5} \pm \mathbf{6 . 8}$ \\
\hline Group 2 $(\mathrm{n}=13)$ & $28 \pm 14.9$ & $47.85 \pm 12.3$ & $89.85 \pm 8.7$ \\
\hline Group 3 $(\mathrm{n}=11)$ & $25.46 \pm 15.3$ & $41 \pm 22.16$ & $76.36 \pm 37.5$ \\
\hline Group 4 $(\mathrm{n}=11)$ & $\mathbf{1 1 . 9 1} \pm \mathbf{1 9 . 6}$ & $26.27 \pm 24.15$ & $\mathbf{5 2 . 5 5} \pm \mathbf{4 3 . 5}$ \\
\hline Group 5 $(\mathrm{n}=9)$ & $12.44 \pm 14.8$ & $\mathbf{2 3 . 8 9} \pm \mathbf{1 8 . 2}$ & $57.78 \pm 37.8$ \\
\hline p-value & $\mathbf{0 . 0 0 1}$ & $<\mathbf{0 . 0 0 1}$ & $<\mathbf{0 . 0 0 1}$ \\
\hline Sig. & $\mathbf{H S}$ & $\mathbf{H S}$ & HS \\
\hline
\end{tabular}

Table 5 illustrates that there is statistically significant difference with $p$-value $<0.05$ between different study groups as regards retro-placental myometrial thickness in $3^{\text {rd }}$ trimesters with low mean thickness was noted among group 1, but the highest mean thickness was noted among group 4 . On the other hand there is no statistically significant difference with $\mathrm{p}$-value $>0.05$ in retro-placental myometrial thickness during $1^{\text {st }}$ and $2^{\text {nd }}$ trimesters.

Table (5): Comparisons of retro-placental myometrial thickness in different study groups.

\begin{tabular}{|l|c|c|c|}
\hline \multirow{2}{*}{ Groups } & \multicolumn{3}{|c|}{ Retro-placental myometrial thickness } \\
\cline { 2 - 4 } & $\mathbf{1}^{\text {st }}$ trimester & $\mathbf{2}^{\text {nd }}$ trimester & $\mathbf{3}^{\text {rd }}$ trimester \\
\cline { 2 - 4 } & Mean \pm SD & Mean \pm SD & Mean \pm SD \\
\hline Group 1 $(n=16)$ & $15.71 \pm 2.5$ & $14.36 \pm 2.4$ & $\mathbf{1 3 . 4 3} \pm \mathbf{2 . 1}$ \\
\hline Group 2 $(\mathrm{n}=13)$ & $14.81 \pm 3.1$ & $14.15 \pm 2.9$ & $13.67 \pm 2.5$ \\
\hline Group 3 $(\mathrm{n}=11)$ & $15.9 \pm 1.9$ & $15.56 \pm 1.8$ & $15.05 \pm 2.1$ \\
\hline Group 4 $(\mathrm{n}=11)$ & $15.01 \pm 4.9$ & $14.95 \pm 4.9$ & $\mathbf{1 5 . 8 8} \pm \mathbf{2 . 9}$ \\
\hline Group 5 $(\mathrm{n}=9)$ & $15.83 \pm 2.7$ & $14.7 \pm 4.4$ & $15.80 \pm 1.5$ \\
\hline p-value & 0.9 & 0.9 & $\mathbf{0 . 0 3}$ \\
\hline Sig. & $\mathrm{NS}$ & $\mathrm{NS}$ & $\mathbf{S}$ \\
\hline
\end{tabular}

Table 6 illustrates that there is no statistically significant difference with p-value $>0.05$ between different study groups as regards GS to OS distance.

Table (6): Comparisons of GS to Os distance in different study groups.

\begin{tabular}{|l|c|c|}
\hline \multirow{2}{*}{\multicolumn{1}{|c|}{ Groups }} & \multicolumn{2}{c|}{ GS to Os distance } \\
\cline { 2 - 3 } & Mean & SD \\
\hline Group 1 $(\mathrm{n}=16)$ & 45.74 & 5.03 \\
\hline Group 2 $(\mathrm{n}=13)$ & 46.37 & 4.1 \\
\hline Group 3 $(\mathrm{n}=11)$ & 44.18 & 4.2 \\
\hline Group 4 $(\mathrm{n}=11)$ & 44.36 & 6.3 \\
\hline Group 5 $(\mathrm{n}=9)$ & 43.97 & 4.9 \\
\hline p-value & \multicolumn{2}{|c|}{0.7} \\
\hline Sig. & \multicolumn{2}{|c|}{$\mathrm{NS}$} \\
\hline
\end{tabular}

Table 7 illustrates that there is statistically significant difference with p-value $<0.05$ between study groups as regards degree of intra-peritoneal adhesion with higher percentage of no adhesion among group 1 (39\%), and mild degree adhesion was among group 2 (30.8\%), and extensive degree of adhesion was noted among group 5 (50\%). 
Table (7): Comparisons of degree of adhesions in different study groups.

\begin{tabular}{|l|c|c|c|}
\hline \multirow{2}{*}{\multicolumn{1}{c|}{ Groups }} & \multicolumn{3}{|c|}{ (Intra-peritoneal adhesion) } \\
\cline { 2 - 4 } & No & Mild & Extensive \\
\cline { 2 - 4 } & No.(\%) & No.(\%) & No.(\%) \\
\hline Group 1 $(\mathrm{n}=16)$ & $\mathbf{1 6 ( 3 9 \% )}$ & $0(0 \%)$ & $0(0 \%)$ \\
\hline Group 2 $(\mathrm{n}=13)$ & $9(22 \%)$ & $\mathbf{4 ( 3 0 . 8 \% )}$ & $0(0 \%)$ \\
\hline Group 3 $(\mathrm{n}=11)$ & $7(17.1 \%)$ & $3(23.1 \%)$ & $1(16.7 \%)$ \\
\hline Group 4 $(\mathrm{n}=11)$ & $6(14.6 \%)$ & $3(23.1 \%)$ & $2(33.3 \%)$ \\
\hline Group 5 $(\mathrm{n}=9)$ & $3(7.3 \%)$ & $3(23.1 \%)$ & $\mathbf{3 ( 5 0 \% )}$ \\
\hline p-value & \multicolumn{3}{|c|}{$\mathbf{0 . 0 2}$} \\
\hline Sig. & $\mathbf{3}$ \\
\hline
\end{tabular}

Table 8 illustrates that there is statistically significant decrease with p-value $<0.05$ in Lower uterine segment thickness, and Retro-placental myometrial thickness and statistical significant increase in length between placenta and uterine OS when progress in pregnancy, from $1^{\text {st }}$ to $3^{\text {rd }}$ trimester among group 1.

Table (8): Comparisons of different measures follow ups in three trimesters of pregnancy among group 1

\begin{tabular}{|c|c|c|c|}
\hline \multirow{2}{*}{ Group 1 } & $\begin{array}{c}\text { Lower uterine } \\
\text { segment thickness }\end{array}$ & $\begin{array}{c}\text { Placenta to Os } \\
\text { length }\end{array}$ & $\begin{array}{c}\text { Retro-placental } \\
\text { myometrial thickness }\end{array}$ \\
\cline { 2 - 4 } & Mean \pm SD & Mean \pm SD & Mean \pm SD \\
\hline $\mathbf{1}^{\text {st }}$ trimester & $14.83 \pm 2.4$ & $34.25 \pm 11.6$ & $15.71 \pm 2.5$ \\
\hline $\mathbf{2}^{\text {nd }}$ trimester & $10.25 \pm 0.98$ & $61.13 \pm 7.2$ & $14.36 \pm 2.4$ \\
\hline $\mathbf{3}^{\text {rd }}$ trimester & $\mathbf{3 . 7 8} \pm \mathbf{0 . 7}$ & $\mathbf{9 9 . 7 5} \pm \mathbf{6 . 8}$ & $\mathbf{1 3 . 4 3 \pm \mathbf { 2 . 1 }}$ \\
\hline p-value & $<\mathbf{0 . 0 0 1}$ & $<\mathbf{0 . 0 0 1}$ & $<\mathbf{0 . 0 0 1}$ \\
\hline Sig. & $\mathbf{H S}$ & HS & HS \\
\hline
\end{tabular}

Table 9 illustrates that there is statistically significant decrease with p-value $<0.05$ in Lower uterine segment thickness, and Retro-placental myometrial thickness and statistical significant increase in length between placenta and uterine OS when progress in pregnancy, from $1^{\text {st }}$ to $3^{\text {rd }}$ trimester among group 2.

Table (9): Comparisons of different measures follow ups in three trimesters of pregnancy among group 2.

\begin{tabular}{|c|c|c|c|}
\hline \multirow{2}{*}{ Group 2 } & $\begin{array}{c}\text { Lower uterine } \\
\text { segment thickness }\end{array}$ & $\begin{array}{c}\text { Placenta to Os } \\
\text { length }\end{array}$ & $\begin{array}{c}\text { Retro-placental } \\
\text { myometrial thickness }\end{array}$ \\
\cline { 2 - 4 } & Mean \pm SD & Mean \pm SD & Mean \pm SD \\
\hline $\mathbf{1}^{\text {st }}$ trimester & $12.22 \pm 2.2$ & $28 \pm 14.9$ & $14.81 \pm 3.1$ \\
\hline $2^{\text {nd }}$ trimester & $8.28 \pm 1.5$ & $47.85 \pm 12.3$ & $14.15 \pm 2.9$ \\
\hline $3^{\text {rd }}$ trimester & $\mathbf{3 . 4 1} \pm \mathbf{0 . 6 2}$ & $\mathbf{8 9 . 8 5} \pm \mathbf{8 . 7}$ & $\mathbf{1 3 . 6 7} \pm \mathbf{2 . 5}$ \\
\hline p-value & $<\mathbf{0 . 0 0 1}$ & $\mathbf{0 . 0 0 1}$ & $<\mathbf{0 . 0 0 1}$ \\
\hline Sig. & HS & HS & HS \\
\hline
\end{tabular}

Table 10 illustrates that there is statistically significant decrease with p-value $<0.05$ in Lower uterine segment thickness, and Retro-placental myometrial thickness and statistical significant increase in length between placenta and uterine OS when progress in pregnancy, from $1^{\text {st }}$ to $3^{\text {rd }}$ trimester among group 3.

Table (10): Comparisons of different measures follow ups in three trimesters of pregnancy among group 3.

\begin{tabular}{|c|c|c|c|}
\hline \multirow{2}{*}{ Group 3 } & $\begin{array}{c}\text { Lower uterine } \\
\text { segment thickness }\end{array}$ & $\begin{array}{c}\text { Placenta to Os } \\
\text { length }\end{array}$ & $\begin{array}{c}\text { Retro-placental } \\
\text { myometrial thickness }\end{array}$ \\
\cline { 2 - 4 } & Mean \pm SD & Mean \pm SD & Mean \pm SD \\
\hline $\mathbf{1}^{\text {st }}$ trimester & $13.84 \pm 1.5$ & $25.46 \pm 15.3$ & $15.9 \pm 1.9$ \\
\hline $\mathbf{2}^{\text {nd }}$ trimester & $8.62 \pm 1.02$ & $41 \pm 22.16$ & $15.56 \pm 1.8$ \\
\hline $\mathbf{3}^{\text {rd }}$ trimester & $\mathbf{3 . 2 1} \pm \mathbf{0 . 4 7}$ & $\mathbf{7 6 . 3 6} \pm \mathbf{3 7 . 5}$ & $\mathbf{1 5 . 0 5} \pm \mathbf{2 . 1}$ \\
\hline p-value & $<\mathbf{0 . 0 0 1}$ & $\mathbf{0 . 0 0 1}$ & $<\mathbf{0 . 0 0 1}$ \\
\hline Sig. & $\mathbf{H S}$ & HS & HS \\
\hline
\end{tabular}


Table 11 illustrates that there is statistically significant decrease with p-value $<0.05$ in lower uterine segment thickness, and statistical significant increase in Retro-placental myometrial thickness and length between placenta and uterine OS when progress in pregnancy, from $1^{\text {st }}$ to $3^{\text {rd }}$ trimester among group 4.

Table (11): Comparisons of different measures follow ups in three trimesters of pregnancy among group 4.

\begin{tabular}{|c|c|c|c|}
\hline \multirow{2}{*}{ Group 4 } & $\begin{array}{c}\text { Lower uterine } \\
\text { segment thickness }\end{array}$ & $\begin{array}{c}\text { Placenta to Os } \\
\text { length }\end{array}$ & $\begin{array}{c}\text { Retro-placental } \\
\text { myometrial thickness }\end{array}$ \\
\cline { 2 - 4 } & Mean \pm SD & Mean \pm SD & Mean \pm SD \\
\hline $\mathbf{1}^{\text {st }}$ trimester & $\mathbf{1 1 . 5 9} \pm \mathbf{1 . 8}$ & $11.91 \pm 19.6$ & $15.01 \pm 4.9$ \\
\hline $\mathbf{2}^{\text {nd }}$ trimester & $8.13 \pm 1.4$ & $26.27 \pm 24.15$ & $14.95 \pm 4.9$ \\
\hline $\mathbf{3}^{\text {rd }}$ trimester & $\mathbf{2 . 9 6} \pm \mathbf{0 . 6 1}$ & $\mathbf{5 2 . 5 5} \pm \mathbf{4 3 . 5}$ & $\mathbf{1 5 . 8 8} \pm \mathbf{2 . 9}$ \\
\hline p-value & $<\mathbf{0 . 0 0 1}$ & $\mathbf{0 . 0 0 5}$ & $\mathbf{0 . 0 0 1}$ \\
\hline Sig. & $\mathbf{H S}$ & HS & HS \\
\hline
\end{tabular}

Table 12 illustrates that there is statistically significant decrease with p-value $<0.05$ in lower uterine segment thickness, and statistical significant increase in Retro-placental myometrial thickness and length between placenta and uterine OS when progress in pregnancy, from $1^{\text {st }}$ to $3^{\text {rd }}$ trimester among group 5.

Table (12): Comparisons of different measures follow ups in three trimesters of pregnancy among group 5.

\begin{tabular}{|c|c|c|c|}
\hline \multirow{2}{*}{ Group 5 } & $\begin{array}{c}\text { Lower uterine } \\
\text { segment thickness }\end{array}$ & $\begin{array}{c}\text { Placenta to Os } \\
\text { length }\end{array}$ & $\begin{array}{c}\text { Retro-placental } \\
\text { myometrial thickness }\end{array}$ \\
\cline { 2 - 4 } & Mean \pm SD & Mean \pm SD & Mean \pm SD \\
\hline $\mathbf{1}^{\text {st }}$ trimester & $12.19 \pm 1.5$ & $12.44 \pm 14.8$ & $15.83 \pm 2.7$ \\
\hline $\mathbf{2}^{\text {nd }}$ trimester & $5.83 \pm 1.2$ & $23.89 \pm 18.2$ & $14.7 \pm 4.4$ \\
\hline $\mathbf{3}^{\text {rd }}$ trimester & $\mathbf{2 . 6 8} \pm \mathbf{0 . 3 5}$ & $\mathbf{5 7 . 7 8} \pm \mathbf{3 7 . 8}$ & $\mathbf{1 5 . 8 0} \pm \mathbf{1 . 5}$ \\
\hline p-value & $<\mathbf{0 . 0 0 1}$ & $\mathbf{0 . 0 0 3}$ & $\mathbf{0 . 0 0 1}$ \\
\hline Sig. & $\mathbf{H S}$ & HS & HS \\
\hline
\end{tabular}

\section{DISCUSSION}

This study has shown some of the effects of repeated hysterotomy on the uterus, specifically lower uterine segment (LUS), \& its surroundings. This topic has been studied profusely in the past due to the importance of LUS thickness in predicting the outcome of vaginal birth after cesarean delivery (VBAC) or Placenta accrete spectrum (PAS) or uterine rupture.

Our findings show a highly significant reduction in the thickness of the myometrium of the LUS as the number of previous CS delivery increases. This is congruent with all the studies done on this subject. In a meta-analysis done by Kok $\boldsymbol{e t}$ $\boldsymbol{a l}{ }^{\left({ }^{(8)}\right.}$ that included 21 studies \& 2776 patients, they stated that the most important factor for predicting success or failure of a trial of labor after CS (TOLAC) or occurrence of uterine rupture was the myometrial thickness. They reached a proposal of myometrial thickness cut-off value of $0.6-2.0 \mathrm{~mm}$ as it provided a strong positive predictive value; while, statistically, a myometrial thickness value of 2.1-4.0 $\mathrm{mm}$ or a whole LUS thickness of $3.1-5.1 \mathrm{~mm}$ provided a strong negative predictive value for the occurrence of uterine defect. The results of our measurements are comparable to those studies.

The issue of the effect of the fetal head pressure or full urinary bladder pressure on the LUS thickness was also discussed \& the results were reported to have improved if the US measurement was taken without the pressure of the fetal head or the urinary bladder, which was noted \& applied in our study, the mothers were asked to apply some degree of traction bilaterally on their lower abdomen while the measurements were taken, if this failed to dislodge the head, a Trendlenburg was used briefly ${ }^{(9)}$.

In our study no TOLAC or VBAC were attempted; due to the risk of medical litigation despite giving a full informed consent, also due to the lack of knowledge \& low educational levels of most of the patients that would make recognition of early symptoms of any complication missed, making it highly dangerous for their outcome. Therefore, only the smallest myometrial thickness during each trimester was the primary outcome measured.

Secondary outcome are many \& include the distance between the leading edge of the placenta $\&$ the internal cervical os during each trimester of the pregnancy to exclude or diagnose cases of placenta praevia. The term low-lying placenta should be used if the placental edge is $\leq 20 \mathrm{~mm}$ away from the internal os at gestational age of 16 weeks or more. Placental location is now advised to be recorded at routine $2^{\text {nd }}$ trimester anomaly scan between 18-22 weeks as the main screening tool for placenta praevia. If the leading edge is found to be $\leq 20 \mathrm{~mm}$ at the 
second trimester scan, a follow-up ultrasound at 32 weeks is recommended including TVUS as mentioned in the Greentop guidelines 27a. Placental migration occurs in $90 \%$ of low-lying placentae due to complete formation of the LUS, however, this is less likely to occur in women with previous history of cesarean sections according to Cho et al. ${ }^{(\mathbf{1 0})}$. These findings are found in this study, where the placenta to os distance is found to have increased as the gestation continues. In one patient with previous 3 CS (group 4) the leading edge of the placenta was only $20 \mathrm{~mm}$ away from the os in the $2^{\text {nd }}$ trimester done at 22 weeks, however it became $11 \mathrm{~mm}$ at 36 weeks; the other case was $11,19 \& 20 \mathrm{~mm}$ at the $1^{\text {st }}, 2^{\text {nd }} \& 3^{\text {rd }}$ trimester scans, respectively, although still remaining low-lying, but the distance clearly increased. Due to the small difference in the distance between the $2^{\text {nd }} \&$ $3^{\text {rd }}$ trimester measurements Placenta accrete spectrum was suspected, coupled by the fact the retroplacental myometrial thickness could not be measured in the $3^{\text {rd }}$ trimester using TVUS; however, placental separation happened without complication at 37 weeks, after step-wise devascularization of the uterus was done.

Ananth et al. ${ }^{(11)}$ a meta-analysis that the RR of placenta praevia increased with the increasing number of previous CS; reporting a RR of 4.5 for previous 1 CS history, 7.4 for previous 2 CS, 6.5 for previous $3 \mathrm{CS}, \& 44.9$ for previous 4 or more CS when compared to normal vaginal deliveries. Another meta-analysis \& systematic review done by Marshal et al. ${ }^{(\mathbf{( 1 2 )}}$ including 22 studies \& more than 2 million deliveries indicated an incidence of 10 in $1000(1 \%)$ in previous 1 CS delivery \& 28 in 1000 (2.8\%) with previous 3 or more CS deliveries for having placenta praevia ${ }^{(12)}$. In my study, only 1 case out of 11 patients with previous 2 CS had placenta praevia, 1 in 11 patients with previous $3 \mathrm{CS}$, in addition to 2 others with low-lying placentae but not praevia. Finally 2 patients with previous 4 CS (group 5) had placenta praevia \& low-lying placentae, respectively the RR of low-lying placentae \& placenta praevia was found to be 9 in group 3, 27 in group $4 \& 22.2$ in group 5. These results were comparable to those published in the meta-analysis (12). More cases in group 4 were found than group 5 but this can be attributed to the small sample size of my study, which was less in group 5 than group 4.

Other risk factors for low-lying placentae were not included in this study including, interpregnancy interval $<1$ year, Assisted reproduction techniques (ART), increased maternal age (> 35 years old) or other reasons for doing hysterotomy in the past. This makes history of hysterotomy in previous CS deliveries the only risk factor studied.

Ultrasound, especially TVUS, is highly accurate when done by a skilled operator. D'Antonio et al $^{\left({ }^{(13)}\right.}$ states in a meta-analysis involving 3707 pregnancies, that TVUS had 96.94 specificity, 90.72 sensitivity \& Diagnostic Odds Ratio (DOR) of $98.6 \%$. Another systematic review by Jauniaux and Bhide $^{(14)}$ reported that $8.4 \%$ of pregnancies had PAS out of which $90 \%$ were diagnosed prenatally ${ }^{(14)}$. Numerous signs have been adopted from D'Antonio et al. ${ }^{(13)}$ meta-analysis \& cited by the Royal College of Obstetricians and Gynaecologists, Cheong et $\boldsymbol{a l}^{(\mathbf{1 5})}$ \& EW-AIP \& their corresponding sensitivity \& sensitivity the detailed description set to standardize the diagnosis of each sign \& a proforma for the prenatal diagnosis has been suggested to decrease missed cases as these signs are subjective \& operator dependent. D'Antonio et al. ${ }^{(\mathbf{1 3})}$ meta- analysis reported that combining colour Doppler imaging with 2D- grey scale imaging increased the negative predictive values to $95.98 \%{ }^{(13)}$. In my study, I used retro-placental remnant myometrial thickness to try to predict cases of PAS.

In our study PAS was found inta-operatively in 2 cases of previous 3 CS deliveries (group 4) \& 2 cases of previous 4 CS (group 5). The retro-placental thickness was affected in 1 case of the group $4 \&$ the 2 cases of group 5 patients. Another patient in group 5 had loss of retro-placental RMT in the $3^{\text {rd }}$ trimester $\&$ placenta praevia but placenta accrete was excluded after placenta separation \& inspection. Other signs was also seen like loss of hypo-echoic zone in 3 cases $\&$ numerous placental lacunae in 1 case. Therefore, 4 out of 44 patients with history of CS had PAS with an overall incidence of $9 \%$ compared to Jauniaux and Bhide ${ }^{(14)} 8.4 \%$, while $18 \%$ of previous 3 CS \& $22.2 \%$ of previous 4 CS had PAS.

Intra-operative adhesions were also assessed in our study. Classification of the degree of adhesions intraoperatively during the cesarean section deliveries into no/mild, moderate \& severe to categorize the results were done. Sliding sign was attempted but could not be elicited in this study, primarily due to the high learning curve it requires as stated by Tammaa et al. ${ }^{(16)}$ and Menakaya et al. ${ }^{(17)}$.

Parker et al. ${ }^{(18)}$ reports a prevalence of postoperative adhesions up to $90 \%$ of surgeries involving the abdomino-pelvic cavities. In our study, the prevalence of moderate adhesions was $30 \%, 27 \%$, $27 \%$ \& $33 \%$ in groups $2,3,4 \& 5$, respectively. Severe adhesions was found in $0 \%, 9 \%, 9 \%, 18 \%$ \& $33.3 \%$ in groups $2,3,4 \& 5$, respectively. The uterus was adherent to the anterior abdominal wall \& could not be exteriorized in 1 case of group $5 \&$ extraperitoneal CS was done in that case $\&$ in another case of group 4. These results are less than those reported by Parker $\boldsymbol{e t}$ al. ${ }^{(18)}$ can be attributed to meticulous hemostasis, trying to minimize tissue handling \& trauma, low transverse uterine incision (1 finger's breadth above the bladder flap) \& careful follow-up 
for signs of infection. Those factors that are postulated by Wiseman et al. ${ }^{(19)}$ to be the probable pathophysiological causes of adhesions by initiating a process of exaggerated inflammation \& subsequent healing by secondary intention \& hence, adhesion formation.

\section{CONCLUSION}

Cesarean section scar pregnancy \& rupture uterus are both rare events \& were not found in the sample of this prospective study. However, they are both very important to diagnose as early as possible to prevent serious morbidity \& even mortality.

\section{REFERENCES}

1. Caspi B, Zbar AP, Mavor E et al. (2003): The contribution of transvaginal ultrasound in the diagnosis of acute appendicitis: an observational study. Ultrasound Obstet Gynecol., 21 (3): 273-6.

2. Rosendahl M, Ernst E, Rasmussen PE et al. (2008): True ovarian volume is underestimated by twodimensional transvaginal ultrasound measurement. Fertil Steril., 93 (3): 995-998.

3. American Congress of Obstetricians and Gynecologists (2013): Five Things Physicians and Patients Should Question, Choosing Wisely: an initiative of the ABIM Foundation. American Congress of Obstetricians and Gynecologists.doi:10.1097/ACOG.0b013e31819cda 77

4. Partridge E, Greenlee AR, Xu RT et al. (2009): Results from four rounds of ovarian cancer screening in a randomized trial. Obstetrics and Gynecology, 113 (4): 775-782.

5. Kulier R, Fekih A, Hofmeyr GJ et al. (2001): Surgical methods for first trimester termination of pregnancy. DOI: 10.1002/14651858. CD002900.

6. Lalitkumar S, Bygdeman $M$ and GemzellDanielsson K (2007): Mid-trimester induced abortion: a review. Hum Reprod Update, 13(1):37-52. 3.

7. Kok N, Wiersma IC, Opmeer BC et al. (2013): Sonographic measurement of lower uterine segment thickness to predict uterine rupture during a trial of labor in women with previous cesarean section: a meta-analysis. Ultrasound Obstet Gynecol., 42(2):132-139.
8. Ginsberg $\mathrm{Y}$, Goldstein I, Lowenstein $\mathrm{L}$ et al. (2013): Measurements of the lower uterine segment during gestation. J Clin Ultrasound, 41(4):214-7.

9. Jastrow $\mathrm{N}$, Demers $\mathrm{S}$, Chaillet $\mathrm{N}$ et al. (2016): Lower uterine segment thickness to prevent uterine rupture and adverse perinatal outcomes: A multicenter prospective study. Am J Obstet Gynecol., 215(5):604-6010.

10. Cho JY, Lee YH, Moon MH et al. (2008): Difference in migration of placenta according to the location and type of placenta previa. J Clin Ultrasound, 36:79-84.

11. Ananth CV, Smulian JC and Vintzileos AM (1997): The association of placenta praevia with history of cesarean delivery and abortion: a metaanalysis. Am J Obstet Gynecol., 177:1071-8.

12. Marshall NE, Fu R and Guise JM (2011): Impact of multiple cesarean deliveries on maternal morbidity: a systematic review. Am J Obstet Gynecol., 205:262270.

13. D'Antonio F, Iacovella $C$ and Bhide A (2013): Prenatal identification of invasive placentation using ultrasound: systematic review and meta- analysis. Ultrasound Obstet Gynecol., 42:509-17.

14. Jauniaux E, Bhide A (2017): Prenatal ultrasound diagnosis and outcome of placenta previa accreta after cesarean delivery: a systematic review and metaanalysis. Am J Obstet Gynecol., 217:27-36.

15. Cheong YC, Premkumar G, Metwally M et al. (2009): To close or not to close? A systematic review and a meta-analysis of peritoneal non-closure and adhesion formation after caesarean section. Eur $\mathrm{J}$ Obstet Gynecol Reprod Biol., 147:3-9.

16. Tammaa A, Fritzer N, Strunk G et al. (2014): Learning curve for the detection of pouch of Douglas obliteration and deep infiltrating endometriosis of the rectum. Hum Reprod Oxf Engl., 29: 1199-1204.

17. Menakaya U, Infante F, Lu C et al. (2016): Interpreting the real-time dynamic 'sliding sign' and predicting pouch of Douglas obliteration: an interobserver, intraobserver, diagnostic-accuracy and learning-curve study. Ultrasound Obstet Gynecol., 48: 113-120.

18. Parker MC, Ellis H, Moran BJ et al. (2001): Postoperative adhesions: ten-year follow-up of 12,584 patients undergoing lower abdominal surgery. Dis Colon Rectum, 44:822-830.

19. Wiseman DM, Trout JR, Franklin RR et al. (1999): Meta analysis of the safety and efficacy of an adhesion barrier (Interceed TC7) in laparotomy. J Reprod Med., 44:325-31. 